\title{
Anthropometric Characteristic, Somatotype and Body Composition of Canadian Female Rowers
}

\author{
Anup Adhikari ${ }^{1}$, Edward McNeely ${ }^{2}$ \\ ${ }^{1}$ Anthropometrica, Toronto, Ontario, Canada \\ ${ }^{2}$ Canadian Sport Institute Ontario, Toronto Pan Am Sports Centre, Toronto, Ontario, Canada
}

Email address:

dranupadhikari@yahoo.com (A. Adhikari)

\section{To cite this article:}

Anup Adhikari, Edward McNeely. Anthropometric Characteristic, Somatotype and Body Composition of Canadian Female Rowers. American Journal of Sports Science. Vol. 3, No. 3, 2015, pp. 61-66. doi: 10.11648/j.ajss.20150303.15

\begin{abstract}
Canadian female rowers were evaluated for their anthropometrical characteristics including somatotype and body composition to evaluate them with their international counterparts. 31 female rowers with an average age of $28.6 \pm 3.4$ ( range 19-33) yr of different local clubs were assessed during their peak season time. Part of the measurements were done during the fulfilment of assignment for ISAK Kianthropometry accreditation course in Canada and part of the measurements were done during the fitness assessment of rowers at local clubs. Somatotype was assessed using Heath- Carter method and body composition (Fat\%) was assessed by surface anthropometry. Endomorphic mesomorph $(3.1 \pm 0.5-4.1 \pm 0.6-2.3 \pm 0.7)$ body type was observed in average with an average $23.4( \pm 2.9) \%$ body fat. Average waist-hip ratio was $0.74( \pm 0.4)$. Canadian female rowers of the present study possessed more than average muscularity with slightly higher body fat \% . The present study recommended more muscularity with less body fat $\%$ for the Canadian female rowers. The study also recommended a change in body type from endomorphic mesomorph to ectomorphic mesomoeph .
\end{abstract}

Keywords: Female Rower, Somatotype, Fat \%, Waist-Hip Ratio, Anthropometric

\section{Introduction}

Physical trait of a sportsman influences the sports performance significantly revealed by different studies [110].The characteristics of physique apparently associated with success in sport and other forms of physical performance [10].Game specific physique is an important factor in sport performance besides other physiological variables and skills. Rowing is a sport where physical traits along with other physiological variables like anaerobic and aerobic power are the most demanding factors to alter the performance $[11,12,13,14]$. Rowing demands high force production where muscularity of the sportsman plays a significant role during pedaling. Thus, physical structure is an important factor that contributes to success in rowing [15]. Most of the previous studies on Rowing focused on physiological and mechanical demands but very few works had been done on somatotype rating of the female rowers [115]. For talent identification as well as for periodization of training program, somatotyping is an important criterion where studies on the rowers can be used as reference. There were very few studies on Canadian female rowers for their anthropometrical aspects and somatotype rating [6,10,11,1619]. Thus, the present study was aimed to evaluate the somatotype traits of Canadian female rowers.

\section{Method}

\subsection{Subjects}

Thirty-one senior level female rowers were measured for their anthropometrical profile from different clubs in Ontario province of Canada. Some of them were from national team and some of them were from local rowing clubs near Toronto but represented national tournaments. All the rowers were from open category involved in regular practice for maintaining their performance level. Part of the data were collected during the assignment given as a part ISAK Kinanthropometry accreditation course and later on used for evaluation. Rest of the data were collected during the fitness measurement session. All the measurements were taken during the practice session. 


\subsection{Anthropometric Measurements}

Anthropometric measurements were done on same day for each player in same session to avoid technical error of measurement. Some of the players were measured by a Level 1 Anthropometrist accredited by International Society for the Advancement of Kinanthropometry (ISAK) [20] and rest of them were measured by a level 4 Criterion Anthropometrist (ISAK). Technical Error of Measurement ( TEM) was followed to avoid the measurement error. Subject consents were taken before the measurements to follow the ethical issues. Methods described in the ISAK manual [21] were followed. Stature was measured with an Anthropometric rod up to $1 \mathrm{~mm}$ and body mass was measured with a digital weighing scale. Skinfold thicknesses were measured with Harpenden skinfold caliper ( Betty Int., UK and CESCORF, Brazil), Anthropometric tape and sliding caliper (CESCORF, Brazil ) were used to measure circumferences and bone diameters respectively.

\subsection{Somatotype}

Heath - Carter [22] method was followed for somatotype rating. The following equations were uses for calculating somatotype.

Endomorphy $=-0.7182+0.1451 \times \sum \mathrm{SF}-0.00068 \times$ $\sum$ SF $2+0.0000014 \times \sum$ SF 3

where $\sum \mathrm{SF}=$ (sum of triceps, subscapular and supraspinale skinfolds) multiplied by $(170.18 /$ height in $\mathrm{cm})$.

Mesomorphy $=0.858 \times$ humerus breadth $+0.601 \times$ femur breadth $+0.188 \times$ corrected arm girth $+0.161 \times$ corrected calf girth - height $\times 0.131+4.5$

Three different equations were used to calculate ectomorphy according to the height -weight ratio (HWR) :

If HWR is greater than or equal to 40.75 then, Ectomorphy $=0.732 \times \mathrm{HWR}-28.58$

If HWR is less than 40.75 and greater than 38.25 then, Ectomorphy $=0.463 \times$ HWR -17.63

If HWR is equal to or less than 38.25 then, Ectomorphy $=$

\subsection{Body Fat \%}

Durnin and Womersley [23] technique was followed for body density. Body fat $\%$ was derived from the equation of Brozek et al [24].

\subsection{Statistical Analysis}

The Statistical Package for Social Sciences ( SPSS v14.0) was used for all descriptive statistics. The results are noted as means and standard deviation.

\subsection{Phantom "z" Score}

The relative magnitudes of physical characteristics with respect to stature were assessed with "Phantom z scores" $[25,26,27]$

\section{Result}

Anthropometric characteristic, somatotype, fat $\%$ and waist -hip ratio of the female rowers of the present study were presented in Table 1 . The average age for the group was 28.6 yr with a range of 19 -33 yr. Endomoprhic mesomorph body type was observed for the female rowers with slightly higher body fat $\%$ compared to female athletic population.

A comparative data for height and body mass, studied by different researchers were presented in Table 2. The average height of the present study was very similar to that of other studies but lower than the 2000 Sydney Olympic rowers.

Table 3 showed a somatotype of various studies along with present study. The Canadian rowers possessed an average somatotype rating of $3.1 \pm 0.5-4.1 \pm 0.6-2.3 \pm 0.7$ with an average endomorphic mesomorph body type.

Fig 1 represented the relative body size of Canadian female rowers as indicated in Phantom z score.

Fig 2 shows the somatotype of female rowers of different studies. 0.1

Table 1. Average somatotype, fat $\%$ and waist-hip ratio of Canadian female Rowers $(n=31)$.

\begin{tabular}{llll}
\hline & mean & SD & Range \\
\hline Age $(\mathrm{yr})$ & 28.6 & 3.4 & $19-33$ \\
Height $(\mathrm{cm})$ & 178.1 & 6.1 & $170-193.5$ \\
Body mass $(\mathrm{kg})$ & 76.5 & 8.0 & $59-93.8$ \\
Endomorph & 3.1 & 0.5 & $2.2-4.2$ \\
Mesomorph & 4.1 & 0.6 & $3.2-5.6$ \\
Ectomorph & 2.3 & 0.7 & $1.1-3.6$ \\
Fat \% & 23.4 & 2.9 & $18.7-27.9$ \\
Waist/Hip Ratio & 0.74 & 0.04 & $0.66-0.83$ \\
\hline
\end{tabular}

Table 2. Comparative table for physical characteristics of different studies.

\begin{tabular}{|c|c|c|c|c|}
\hline Studies & Rower & Age (yr) & Height(cm) & Body mass(kg) \\
\hline Hebbelinck et al (1980) & Montreal Olympic, 1976 & $23.8 \pm 2.7$ & $174.3 \pm 4.8$ & $67.4 \pm 5.3$ \\
\hline Carter et al (1982) & Montreal Olympic, 1976 & $23.1 \pm 2.3$ & $175.8 \pm 4.4$ & $68.3 \pm 5.8$ \\
\hline Rodŕiguez (1986) & World Championship & $24.1 \pm 3.7$ & 167.1 & $57.1 \pm 2.0$ \\
\hline Carter and Heath(1990) & North American & & 179.2 & 66.6 \\
\hline Bourgois et al (2001) & Belgian Dutch & $17.5 \pm 0.8$ & 175.2 & 70.1 \\
\hline Slater et al (2005) & Australian Light wt & $<23$ & $170.0 \pm 5.3$ & $57.4 \pm 1.6$ \\
\hline
\end{tabular}




\begin{tabular}{|c|c|c|c|c|}
\hline Studies & Rower & Age (yr) & Height(cm) & Body mass(kg) \\
\hline \multirow{3}{*}{ Kerr et al, (2007) } & Australian Open & $<23$ & $170.3 \pm 3.5$ & $57.9 \pm 1.1$ \\
\hline & Sydney Olympic,2000 Light wt & $26.0 \pm 2.9$ & $169.2 \pm 5.1$ & $58.5 \pm 1.5$ \\
\hline & Sydney Olympic, 2000 Open & $27.8 \pm 4.4$ & $180.8 \pm 4.7$ & $76.6 \pm 5.2$ \\
\hline Forjasz (2011) & Polish & $17.0 \pm 0.7$ & $177.7 \pm 6.0$ & $75.7 \pm 4.4$ \\
\hline Present study & Canadian & $28.6 \pm 3.4$ & $178.1 \pm 6.1$ & $76.5 \pm 8.0$ \\
\hline
\end{tabular}

Table 3. Comparative table for somatotype of female rowers, Endo $=$ Endomorph, Meso $=$ Mesomorph, Ecto $=$ Ectomorph .

\begin{tabular}{|c|c|c|c|c|c|c|c|}
\hline Studies & Rowers & Age (yr) & Ht(cm) & Wt(kg) & Endo & Meso & Ecto \\
\hline Hebbelinck et al(1980) & Montreal Olympic,1976 & $23.8 \pm 2.7$ & $174.3 \pm 4.8$ & $67.4 \pm 5.3$ & $3.1 \pm 0.8$ & $3.9 \pm 0.9$ & $2.8 \pm 0.8$ \\
\hline Carter et al 1982 & Montreal Olympic,1976 & $23.1 \pm 2.3$ & $175.8 \pm 4.4$ & $68.3 \pm 5.8$ & $3.2 \pm 1.0$ & $3.9 \pm 0.5$ & $2.9 \pm 0.6$ \\
\hline Carter and Heath,1990 & North American & & 179.2 & 66.6 & 3.0 & 4.0 & 4.0 \\
\hline Meszaros and Mohacsi,1982a & Hungarian & & Not available & Not available & 3.5 & 5.0 & 3.0 \\
\hline \multirow{2}{*}{ Slater et al (2005) } & Australian Light wt & $<23$ & $170.0 \pm 5.3$ & $57.4 \pm 1.6$ & $2.5 \pm 0.6$ & $3.3 \pm 0.9$ & $3.7 \pm 0.9$ \\
\hline & Australian Open & $<23$ & $170.3 \pm 3.5$ & $57.9 \pm 1.1$ & $2.4 \pm 0.7$ & $3.3 \pm 0.7$ & $3.7 \pm 0.6$ \\
\hline Bourgois et al (2001) & World Jr. Rowing Championship & $17.5 \pm 0.8$ & 175.2 & 70.1 & 3.1 & 3.4 & 2.6 \\
\hline Present study & Canadian & $28.6 \pm 3.4$ & $178.1 \pm 6.1$ & $76.5 \pm 8.0$ & $3.1 \pm 0.5$ & $4.1 \pm 0.6$ & $2.3 \pm 0.7$ \\
\hline
\end{tabular}

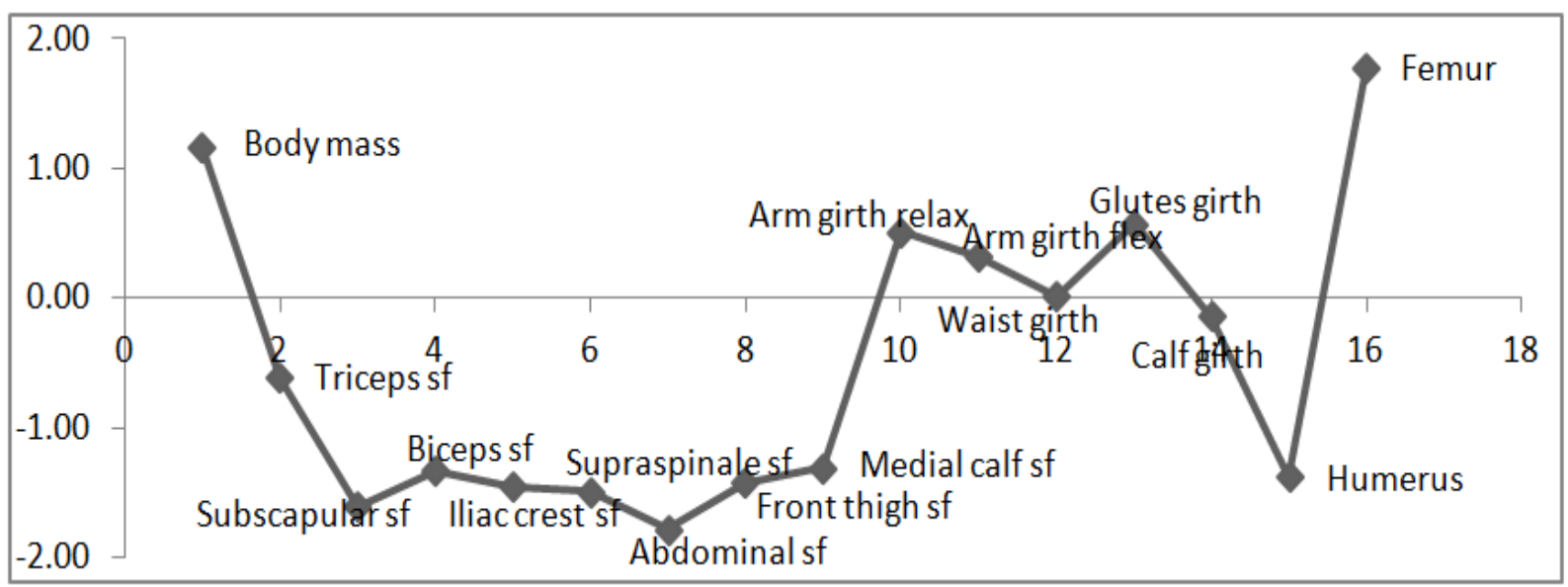

Fig. 1. Relative body size of Canadian female rowers, as indicated in phantom z score.

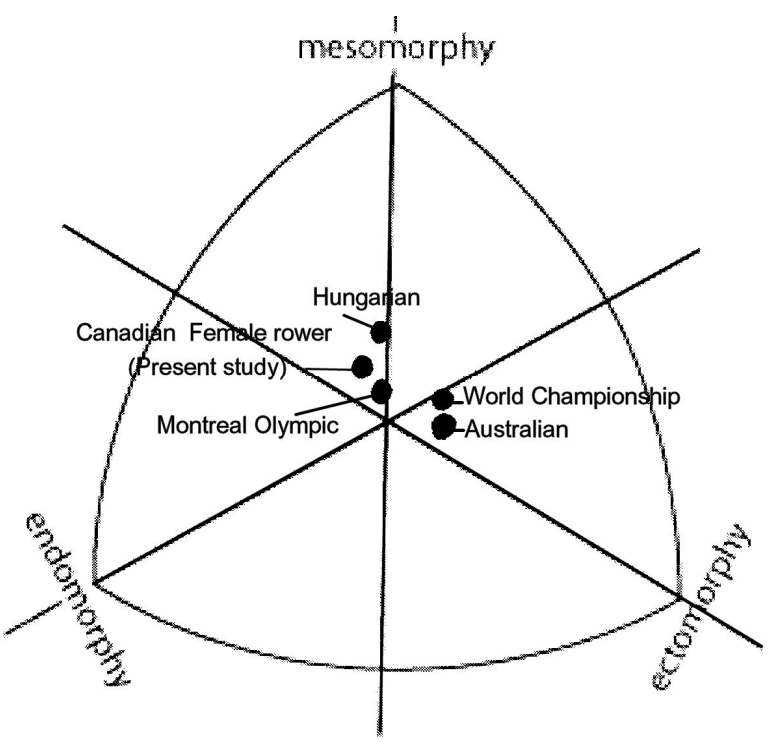

Fig. 2. Somatochart for the female rowers of different studies.

\section{Discussion}

The aim of the present study was to find out the anthropometrical trait of Canadian senior level female rowers along with somatotype trait as physique traits were very much related to the performance level, revealed by different studies [1-10].

Stature is an important factor in rowing which helps to get more mechanical help to create more force during rowing [11, $18,19]$. In rowing tall athletes have an advantage of their long arms and legs for paddling much longer [ 11,14,18, 19]. Data from elite adult rowers had shown that lean body mass and body dimensions were related to performance because they were significant determinants of muscle strength and range of motion during rowing $[11,13,18,19]$. The elite rowers were usually taller and heavier [15, 16, 28, 29] than the less successful rowers and also taller and heavier than athletes of other sports[10,17].Some literature supported tall stature for female rowers which was approximately $180 \mathrm{~cm}$ [30,31].In the present study, observed average height of the Canadian female rowers was $178.1( \pm 6.1) \mathrm{cm}$ with a range of 170 $193.5 \mathrm{~cm}$ which was higher than the female rowers of Montreal Olympic games 1976 and 1985 World Championship (Table 2) but very similar to $179.2 \mathrm{~cm}$ stated by Heath and Carter for North American rowers [32]. Australian female rowers under 23 yr possessed an average value of $170(+5.3) \mathrm{cm}$ [18].Similarly Iranian junior female rowers possessed very similar value of $170.3(+4.1) \mathrm{cm}[11]$. 
Belgian Dutch junior female rowers also possessed an average value of $175.2 \mathrm{~cm}$ [19], whereas Rodŕiguez (1986) reported a lower value of $167.1 \mathrm{~cm}$ in average for the senior female rowers. Thus, the Canadian senior female rowers are taller than their female counterparts of Australia, Iran, Poland, Belgium ( Table 2) though some of them were from junior groups.

When body mass was considered, Canadian female rowers of the present study were heavier than their counterparts of other countries and also heavier from the participants of 1976 Montreal Olympic and 1985 World Championship ( Table 2).

The somatotype rating of the present study was $3.1-4.1-2.3$ with a standard deviation of $0.5-0.6-0.7$ respectively for endomorph, mesomorph and ectomorph. Hebbelink et al [16] and Carter et al [17] worked on the female rowers who had participated in 1976 Montreal Olympic ( Table 3). While Carter et al (1982) observed an average value of $3.2 \pm 1.0-3.9 \pm 0.5-2.9 \pm 0.6$ for an isolated group of female Olympic rowers [ 17], Hebbelinck et al (1980) observed very similar value of $3.1 \pm 0.8$ $-3.9 \pm 0.9-2.8 \pm 0.8$ for all female rowers participated in Montreal Olympic [ 16]. In 1990, Carter and Heath reported a value of 3-4-4 for the female rower with tall stature than the Montreal Olympians [32]. Meszaros and Mohacsi [1982a] reported a higher value for mesomorph component for the Hungarian female rowers with an average somatotype rating of 3.5-5-3 [32]. Australian female rowers possessed an average somatotype rating of $2.5 \pm 0.6-3.3 \pm 0.9-3.7 \pm 0.9$ whereas their open female counterparts measured with an average value $2.4 \pm 0.7-3.3 \pm 0.7-3.7 \pm 0.6$ [18]. Bourgois et al [2001] worked on the junior female rowers 1997 World Junior Rowing Championship and reported an average somatotype rating of 3.1-3.4-2.6

( estimated from the published data ) [19]. Rodŕiguez (1986) also worked on senior female rowers of 1985 World Championship and reported an average somatotype rating of $2.4 \pm 0.8-3.0 \pm 1.1-3.5 \pm 1.0$ [6 ]. Kerr et al (2007) reported an average tall height for the female rowers participated in Sydney Olympic [31].

Thus, various body types of female rowers were reported by different studies. Some researchers reported endomorphic mesomorph body type [19,33] including the present study, whereas some workers reported balanced mesomorph $[16,17]$ or mesomorphic ectomorph [18,32]. Carter et al [17] reported that $60 \%$ participants of 1976 Montreal Olympic female rowers had central or balanced mesomorph somatotypes . Due to unavailability of sufficient literatures on female rowers of different countries, it was very difficult to comment on ideal somatotype of female rowers. Most of the rowers of reported literatures available [ 6,16,17,18,19,32,33] including the present study were concentrated over or around the central zone deviating towards endomorphic zone (Fig 2), suggesting a possible trait of endomorphic mesomorph body type for the female rowers.

In rowing, muscle mass has a significant role as the sport requires strength and endurance. Thus identifying mesomorph component which represents the muscularity, is an important factor for evaluation of a rower. When mesomorph component was considered, an average value of $4.1 \pm 0.6$ was observed in the present study, which was higher than the average value but close to the central. The value was slightly higher than the Montreal Olympic rowers [16,17], but lower than 5.0 for the Hungarian rowers [ 33]. The Canadian female rowers of the present study possessed more muscularity in terms of mesomorph component than the rowers of Australia [18] and rowers of World championship $[6,19]$.

Amount of fat present in the body had a significant role in sport performance [34,35]. A certain amount of fat is required for maintenance of body metabolism but excess adiposity has a negative influence in performance level. Other studies showed that female athletes had a range of 8.4 to 28 percent body fat depending on the type of sport . Female body builders possessed a minimum 8.4 percent body fat whereas female shot putters reported had the maximum value of $28 \%$ [35]. Wilmore et al [36] reported an average $22 \%$ body fat for senior soccer players. The Canadian female rowers of the present study possessed an average value of $23.4( \pm 2.9) \%$ body fat with a range of 18.7-27.9 which was in normal range, compared to the body fat $\%$ of different female athletes reported by different studies $[35,36]$. The Canadian female rowers of the present study possessed slightly higher percent of fat than the reported $22.1 \pm 3.1 \%$ for the Canadian junior soccer players [37] and but less than 31.8 percent reported for sedentary Canadian women [38].

According to World Health Organisation (WHO), WaistHip ratio is an indicator of obesity [39]. A Waist Hip ratio of 0.7 or less for women had been shown to correlate strongly with general health and physical fitness [40]. Average Waist Hip ratio of $0.74( \pm 0.04)$ for the Canadian female rowers of the present study indicated a good general health and physical fitness.

From the above discussion it might be concluded that the Canadian female rowers had an endomorphic mesomorph somatotype with a more than average mesomorphic component which should be improved. The average body fat \% was in normal range, but it should be slightly go down to change the body type into ectomorphic mesomorph from endomorphic mesomorph. More studies were recommended for future references.

\section{References}

[1] Markoviæ, G., Durakovie, M. M., S., Trnini, Fitness profile of elite Croatian female Taekwondo athletes, Collegium Antropologicum, vol. 29, no 1, pp. 93-99, 2005.

[2] Shephard, R., J., Science and medicine of rowing: a review. Journal of Sports Science, vol. 16, pp. 603-620, 1998.

[3] Olds, T., The evolution of physique in male rugby union players in the twentieth century. Journal of Sports Science, vol. 19, pp. 253-62, 2001. 
[4] Siders, W., A., Lukaski, H., C., W. W., Bolonchuk, Relationships among swimming performance, body composition and somatotype in competitive collegiate swimmers, Journal of Sports Medicine and Physical Fitness, vol. 33, pp. 166-171. 1993.

[5] White, A. T, S. C. Johnson, Physiological comparison of international, national and regional alpine skiers, International Journal of Sports Medicine, vol. 12, pp. 374-378, 1991.

[6] Rodriguez, F. A. Physical structure of international lightweight rowers. In:Reilly $\mathrm{T}$, Watkins J, Borms J, eds. Kinanthropometry III. London: E and FN Spon, 1986, pp255261.

[7] Fry, A. C., Ryan, A. J., R. J. Schwab, Anthropometric characteristics as discriminators of body-building success, Journal of Sports Science, vol. 9, pp. 23-32, 1991.

[8] Faria, I. E., E. W. Faria, Relationship of the anthropometric and physical characteristics of male junior gymnasts to performance, Journal of Sports Medicine and Physical Fitness, vol 29, pp 369-78, 1989.

[9] Norton, K., Olds, T., S. Olive, Anthropometry and sports performance. In:Norton K, Olds T, eds. Anthropometrica. Sydney: University of New South Wales Press, 1996, pp. 287364.

[10] Carter, J. E. L., B. H. Heath, Sport and Physical Performance, in Somatotyping -Development and Applications, Cambridge, Cambridge University Press, 1991, pp 198-286.

[11] Arazi, H., Faraji, H., S. M. Mohammadi , Anthropometric and Physiological Profiles of Elite Iranian Junior Rowers, MiddleEast Journal of Scientific Research, vol. 9, no2, pp. 162-166, 2011.

[12] Ingham, S. A., Whyte, G. P., Jones, K., A. M. Nevill, Determinants of $2,000 \mathrm{~m}$ rowing ergometer performance in elite rowers, European Journal of Applied Physiology, vol. 88, pp. 243-246, 2002.

[13] Jürimäe, T., Perez-Turpin, J. A., Cortell-Tormo, J. M., . Chinchilla-Mira, I. J., Cejuela-Anta, R., Mäestu, J., Purge, P., J. Jürimäe, Relationship between rowing ergometer performance and physiological responses to upper and lower body exercises in rowers, Journal of Science and Medicine in Sport, vol. 13, pp 434-437, 2010.

[14] Secher, N. H., Rowing. In R. J. Shephard and P. O. Astrand, (Eds. ). Endurance in sport. Oxford: 2000, Blackwell Science.

[15] Kaloupsis, S., G. C. Bogdanis , E. Dimakopoulou , M. Maridaki , Biology of Sport, vol. 25, no 1, pp. 57-69, 2008

[16] Hebbelinck, M., Ross, W. D., Carter, J. E. L., J. Borms, Anthropometric Characteristics of female Olympic rowers, Canadian Journal of Applied Sport Sciences, vol. 5, pp. 255262, 1980.

[17] Carter, J. E. L., Aubry, S. P., D. D. A. Sleet, Somatotype of Montreal Olympic athletes. In Physical structure of Olympic athletes, Part I. the Montreal Olympic games Anthropological project, ed J. E. L. carter, 1982, pp. 53-80, Basel:Karger.

[18] Slater, G. I., Rice, A. J., Mujika, I., Hahn, A. G., Sharpe, K., D G. Jenkins, Physique traits of lightweight rowers and their relationship to competitive success, British Journal of Sports Medicine, vol. 39, pp. 736-741, 2005
[19] Bourgois, J, Claessens, A. L., Janssens, M., van Renterghem, B., Loos, R., Thomis, M., Philippaerts, R., Lefevre, J., J. Vrijens, Anthropometric characteristics of elite female junior rowers, Journal of Sports Sciences, vol. 19, pp. 195-202, 2001.

[20] International Society for the Advancement of Kinanthropometry(ISAK), available at www.isakonline.com

[21] ISAK, International Standards for Anthropometric Assessment, ISAK manual International Society for the Advancement of Kinanthropometry (ISAK), 2011, Lower Hutt, New Zealand.

[22] Heath, B. H., J. E. L. Carter, A modified somatotype method, American Journal of Physical Anthropology, vol. 27, pp. 5774, 1967.

[23] Durnin, J. V. G. A., J. Womersly, Body fat assessed from total body density and its estimation from skinfold thicknesses, British Journal of Nutrition, vol. 32, pp. 77-79, 1974.

[24] Brozek, J., Grande, F., Anderson, J. T., A. Keys, Densiometric analysis of body composition : revision of some quantitative assumption, Annals of the New York, Academy of Sciences, 1963, vol. 110, pp. 113-140.

[25] Ross, W. D., N. C. Wilson, A stratagem for proportional growth assessment. Acta Paediatrica Belgica, (Suppl. 28), pp. 169-182, 1974.

[26] Ross, W. D., R. Ward, Sexual dimorphism and human proportionality. In R. Hall (Ed. ), Sexual dimorphism in homo sapiens, 1982, pp. 317-361, New York: Praeger.

[27] Ross, W. D., Drinkwater, D. T., Bailey, D. A., Marshall, G. H., R. M. Leahy, Kinanthropometry: Traditions and new perspectives. In M. Ostyn, G. Beunen, \& J. Simons (Eds. ), Kinanthropometry II (pp. 1-27). 1980, Baltimore: University Park Press.

[28] Bourgois, J., Claessens, A. L., Vrijens, H., Philippaerts, R., Van Renterghem, B., Thomis, M., Janssens, M., Loos, R., J. Lefevre, Anthropometric characteristics of elite male junior rowers, British Journal of Sports Medicine. vol. 34, pp. 213 $217,2000$.

[29] Secher, N. H., O. Vaage , Rowing performance, a mathematical model based on analysis of body dimensions as exemplified by body weight, European Journal of Applied Physiology, vol. 52, pp. 88-93, 1983.

[30] Dağıstanl, M. A., Spor Kitabı, Oyunlar kurallar taktikler teknikler. NTV, Publications. İstanbul, 2008, pp. 256-260.

[31] Kerr Deborah A., Ross, W. D., Norton Kevin, Patricia Hume., Masaharu Kagawa, Olympic Lightweight and Open-Class Rowers Possess, Distinctive Physical and Proportionately Characteristics. Journal of Sports Sciences, vol. 25, no1, pp. : 43-53, 2007.

[32] Carter, J. E. L., B. H. Heath, Sport and Physical Performance, in Somatotyping -Development and Applications, Cambridge, Cambridge University Press, 1990, pp. 266-267.

[33] Mészáros, J., J. Mohácsi , The somatotype of hungarian male and female class I paddlers and rower. Anthropologiai Közlemények, vol. 26, pp. 175-179, 1982a.

[34] Carter, J. E. L., B. H. Heath, Somatotyping-development and applications, Cambridge University Press, Cambridge, 1990, pp. 181-291. 
[35] McArdle, W. D., Katch, F. I., V. L. Katch, Exercise physiology-Energy, Nutrition and Human Performance, 5th ed, lippincott Wliiliams \& Wilkins, Philadelphia, 2001, pp. 794819.

[36] Wilmore, J. H., Broen, C. H., Physiological profiles of women distance runners, Medicine and Science in Sports , vol. 6, pp. $178-182,1974$

[37] Anup Adhikari, Jady Nugent. Anthropometric Characteristic, Body Composition and Somatotype of Canadian Female Soccer Players, American Journal of Sports Science, Special
Issue: Science \& Soccer, vol. 2, no 6-1, pp. 14-18, 2014.

[38] Anup Adhikari, "Prevalence of Obesity among Immigrants Living in Canada. " American Journal of Sports Science and Medicine, vol. 2, no1, pp. 35-39, 2014.

[39] World Health Organisation (WHO), Step wise approach to surveillance (STEP), World Health Organisation, Retrieved, March, 2012.

[40] Shibili Nuhmani, Nasreen Akthar, Anthropometry and Functional performance of elite Indian junior Tennis players, Journal of Science, vol. 4, no 1, 55-59, 2014. 